\title{
Good news for universities
}

\section{Tokyo}

JAPAN's Ministry of Education, Science, and Culture (MESC) is at last attempting to infuse some new funds into Japan's rundown university research system. The ministry has requested substantial increases in next year's budget for competitive grants and fellowships to support university research and to reform the engineering and science faculties of Tokyo University, Japan's leading national university. But the new funds are being made available only by squeezing other parts of the ministry's research system.

The ministry's budget request, submitted at the end of last month, is subject to approval by the Ministry of Finance and the Diet and may undergo minor trimming, but substantial changes are unlikely.

Western scientists visiting Japan are often appalled by the rundown state of many of the research laboratories of annual general maintenance funds for research teams (koza) by 25 per cent, or several million dollars, over the next two years. And even more funds will be required in coming years if Tokyo University is to be converted into a 'centre of excellence' as reformers plan.

But to release the extra funds for the universities, the ministry has asked some of its large national research institutes, such as the three laboratories for physiological science, molecular science and basic biology in Okazaki near Nagoya, to carry out their next three-year plan in a five-year period and thereby reduce the annual allocation of funds to these institutes.

The ministry's support for human genome research also seems likely to suffer. Ministry officials say they expect grants for genome research to be about the same as this year, at around $¥ 400$ million (\$3 million), despite earlier hopes of a large increase in funds for the human genome project over the coming years.

BUDGET REQUEST FOR MINISTRY OF EDUCATION, SCIENCE AND CULTURE

\begin{tabular}{lrr}
\hline & $\begin{array}{r}\text { thousand } \\
\text { million yen }\end{array}$ & $\begin{array}{r}\% \text { change } \\
\text { from 1991 }\end{array}$ \\
Grants-in-aid of research & 65.1 & +10.5 \\
Government/industry research & 16.8 & +25.3 \\
Donations from industry & 48.1 & +8.7 \\
Nuclear fusion & 10.6 & +20.7 \\
Accelerator physics (TRISTAN) & 14.3 & -9.4 \\
Space science & 21.0 & +1.0 \\
Astronomy & 3.2 & +90.0 \\
Earth science & 2.3 & +1.1 \\
Antarctic research & 3.7 & +20.1 \\
& &
\end{tabular}

Japan's leading national universities. Calls for a dramatic increase in budget for university research have been increasing in volume in recent years. Akito Arima, president of Tokyo University, has been particularly vocal in his demands for reform.

MESC wants to boost the budget for competitive research grants, which go to university and other MESC researchers, by more than 10 per cent to $¥ 65,100$ million ( $\$ 482$ million). This is the biggest increase requested in years, but it still runs far short of the doubling in budget that leading academics say is needed.

The ministry hopes to support an extra 300 young scientists and engineers at the universities with postdoctoral and graduate fellowships. And MESC will boost the salaries for next year's 1,400 fellowships by 10 to 23 per cent, all of which will require a 47 per cent increase in the fellowship budget to $¥ 3,458$ million ( $\$ 26$ million).

The ministry has also applied for extra funds to reform the graduate school of Tokyo University (Nature 351, 679; 27 June 1991). Details of the request are not yet available, but the engineering and science faculties are hoping to increase the
Furthermore, MESC is requesting only about $¥ 100$ million for facilities and equipment for a new genome-analysis centre at the medical science institute of Tokyo University. This small request will effectively kill plans by the centre to purchase a supercomputer, at least for the time being. And MESC hopes to increase the number of researchers at the centre only from four to five. In contrast, the Science and Technology Agency is requesting an increase of more than 50 per cent in funds for human genome research in 1992, to $¥ 1,520$ million (Nature 353, 3; 5 September 1991).

Despite the squeeze to help the universities, MESC continues to give strong support to space science and astronomy. About $¥ 613$ million ( $\$ 4.5$ million) has been allocated for the purchase of giant photomultiplier tubes for what will be the world's largest observatory for neutrinos and proton decay. Plans to build the observatory, called Superkamiokande, in a mine in Gifu Prefecture have been in the works for several years. Funds for excavation of a hole for Superkamiokande are included in this year's budget, but this is the first commitment by MESC to building the detector.

The budget for construction of an 8-metre infrared telescope in Hawaii accounts for most of the rest of the large increase requested for astronomy. And construction of a giant helical fusion device at the new national fusion research institute in Gifu Prefecture takes up much of the increased budget for fusion. But funds for the huge electron-positron collider TRISTAN continue to fall, with operating time being cut by 200 hours to 2,600 hours next year.

The Institute of Space and Astronautical Science, on the other hand, maintains a healthy budget of more than $¥ 20,000$ million. About $¥ 100$ million in new funds is requested for the institute to prepare for a mission to Mars in 1996 (see Nature $\mathbf{3 6 3}$ 8; 5 September 1991).

David Swinbanks

\section{JAPANESE SATELLITES}

\section{New testing centre}

Tokyo

HAVING failed to exclude foreign suppliers from Japan's lucrative commercial satellite market, the Ministry of Posts and Telecommunications, backed by the government and private companies, plans to establish a satellite testing facility next year to help raise the competitive level of Japan's satellite industry.

The ministry announced last week that it has applied for funds in next fiscal year's budget to set up the new facility, which is expected to cost about $¥ 12,000$ million $\mathbf{\$ 8 9}$ million). The government will provide about one-third of the funds for the centre, while the remaining two-thirds will come from private companies, which are expected to include NEC, Toshiba, Hitachi and Mitsubishi Electric.

Last year, under US pressure, Japan agreed to drop plans by the government's National Space Development Agency to build and launch next-generation communication and broadcast satellites for commercial purposes. Instead, bidding for the supply of such commercial satellites will be open to foreign as well Japanese concerns.

Western (in particular US) companies are strongly placed to win the bids for satellites to be launched in the mid-1990s. And observers say that this is why the government hopes to improve the competitiveness of Japan's industry by establishing the new research centre. D.S.

\section{Sunlight in orbit}

\section{Tokyo}

SunLIGHT $(\overline{y o} k \bar{k})$ is the name given to Japan's latest X-ray observation satellite, Solar-A, which was launched without a hitch on 30 August by the Institute of Space and Astronautical Science from its Kagoshima space centre in Uchinoura in southern Japan. $Y \bar{o} k \bar{o}$, which is orbiting between 520 and $770 \mathrm{~km}$ above the Earth, will observe solar flare activity of the Sun during the present solar maximum using hard and soft $X$-ray telescopes and $X$-ray spectrometers developed in collaboration with US and UK scientists (Nature 352, 96; 11 July 1991). After the equipment has been tested, observations of the Sun are expected to start later this month. D.S. 